\title{
Total disc replacement in the cervical spine: a systematic review evaluating long-term safety
}

Authors Paul A Anderson ${ }^{1}$, Robin Hashimoto ${ }^{2}$

Institutions ${ }^{1}$ Department of Orthopedics $\delta$ Rehabilitation, University of Wisconsin, Madison, WI, USA

${ }^{2}$ Spectrum Research Inc, Tacoma, WA, USA

\section{ABSTRACT}

Study design: Systematic review.

Clinical questions: What are the rates and causes of subsequent surgeries? What is the long-term complication rates following cervical artificial disc replacement (C-ADR)? How do these rates change over time?

Methods: A systematic review was undertaken for articles published up to October 2011. Electronic databases and reference lists of key articles were searched to identify comparative and non-comparative studies reporting long-term ( $\geq 48$ months) complications of C-ADR. Two independent reviewers assessed the strength of evidence using the GRADE criteria and disagreements were resolved by consensus.

Results: Two RCTs reporting outcomes following C-ADR (Bryan disc, Prestige disc) versus anterior cervical discectomy and fusion (ACDF) at follow-ups of 4 to 5 years were found; five case series reporting outcomes following C-ADR at follow-ups of 4 to 8 years were identified. Secondary surgery rates were similar or slightly lower following C-ADR compared with fusion at 4 to 5 years postoperatively. In one small subset of an RCT, rates of adjacent disc heterotopic ossification were lower in C-ADR patients than in those treated with fusion. Rates of other adverse events were similar between treatment groups.

Conclusions: There is low evidence on the long-term safety outcomes following C-ADR. Additional comparative studies with follow-up of at least 4 years are needed to fully understand the long-term safety outcomes of C-ADR compared with fusion. 


\section{STUDY RATIONALE AND CONTEXT}

Theoretical advantages of cervical artificial disc replacement (C-ADR) are to decrease abnormal biomechanical forces at adjacent segments, thereby decreasing the risk of degeneration and need for subsequent surgery. Evidence from RCTs with 2 years follow-up has shown equal or slightly better clinical outcomes and complication rates between C-ADR and fusion. Further follow-up is needed to determine the long-term rates of reoperation and adverse events of a new technology such as C-ADR to determine if unexpected failure mechanisms are present.

\section{CLINICAL QUESTIONS}

1. What evidence is available from studies of C-ADR regarding the long-term complications? How do these rates change over time?

2. What are the rates and causes of second surgeries?

Fig 1 Results of literature search.

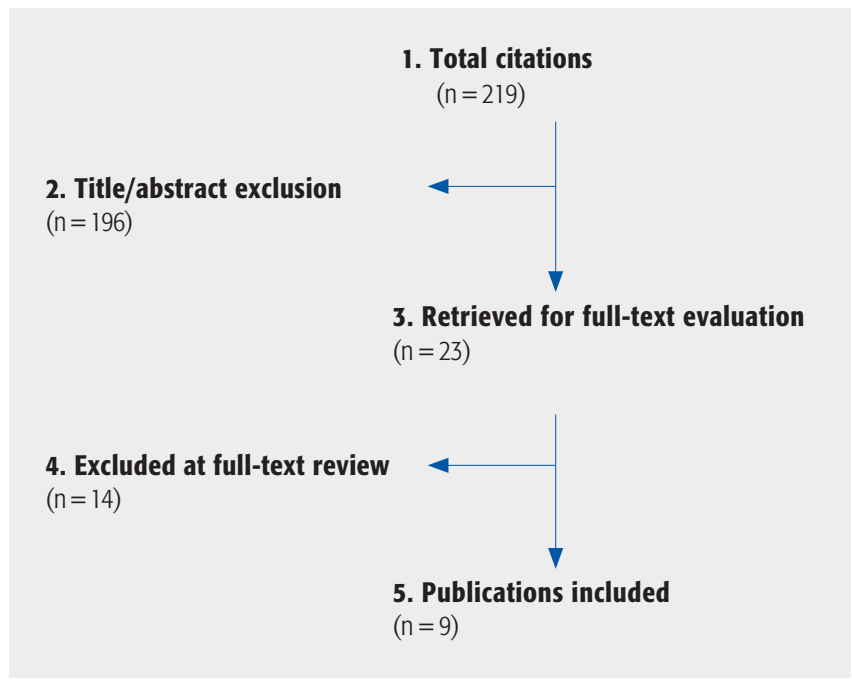

\section{MATERIALS AND METHODS}

Study design: Systematic review.

\section{Sampling:}

Search: PubMed, Cochrane collaboration database, and National Guideline Clearinghouse databases; bibliographies of key articles (Fig $\mathbf{1}$ ).

Dates searched: through October 1, 2011.

Inclusion criteria: (1) comparative and non-comparative studies reporting on complications (including revision) following C-ADR; (2) follow-up $\geq 4$ years.

Exclusion criteria: (1) mean follow-up <4 years; (2) adjacent segment disease; and (3) device survival.

Outcomes: Revision, reoperation, complications (including, but not limited to heterotopic ossification, radiculopathy, dysphagia, fracture, subsidence).

Analysis: Descriptive statistics.

Additional methodological and technical details are provided in the Web Appendix at www.aospine.orglebsj 


\section{RESULTS}

A total of two RCTs were identified:

- Two randomized, multicenter FDA trials [1-3] comparing outcomes following C-ADR and anterior cervical discectomy and fusion (ACDF) at 48 and 60 months postoperatively were identified.

- Discs evaluated included Bryan (48 months) $[2,3]$ and Prestige (60 months) [1].

- A total of 1004 adult patients (47\% male) with a mean age of 44.0 years were enrolled. All patients were diagnosed with single-level degenerative disc disease between $\mathrm{C} 3$ and $\mathrm{C} 7$ and had failed a minimum of 6 weeks conservative treatment. Complete follow-up in the two RCTs was low, ranging from $50 \%-75 \%$.

- Both RCTs received a class of evidence (CoE) grade II.

Five case series (in six reports) were also identified ( $\mathrm{N}=$ 216) [4-9].

- Follow-up rates ranged from 4 to 8 years.

- Discs evaluated included Prestige [6] (4 years), ProDisc-C [7] (4 years), and Bryan [4, 5, 8, 9] (4-8 years).

- All case series are CoE IV studies.

\section{Subsequent operations}

RCTs (Tables 1-2)

- At 48 months, one RCT reported no significant differences between groups for rates of revisions, hardware removal, supplemental fixation, use of bone growth stimulators, or reoperation [2].

- At 60 months, one RCT reported significant difference between the C-ADR and ACDF groups, respectively, in revisions ( $0 \%$ versus $1.9 \% ; P=.028)$, supplemental fixation $(0 \%$ versus $1.9 \% ; P=.028)$, and the use of external bone growth stimulator $(0 \%$ versus $2.6 \%$; $P$ $=.007$ ) [1].

- Causes of subsequent reoperation varied (Table 2). Most studies reported a range regarding when secondary procedures took place, making it difficult to determine their precise timing.

\section{Case series (Tables 3-4)}

- At 4-8 years follow-up, subsequent reoperation rates were low: hardware removal (1.5\%) [4-7], reoperation at the index level (1.5\%) [4-7], and surgery at other cervical levels $(4.3 \%)$ [4-6]. No patients had undergone revisions or supplemental fixation at the index level [4-7].

- Causes and timing of second surgeries varied (Table 4).

\section{Adverse events}

RCTs (Table 5)

- A single-site report of a larger RCT study reported lower rates of adjacent-level ossification at both 2 and 4 years $(24 \%$ vs $64 \% ; P=.003)$ and $(50 \%$ vs $82 \% ; P=$ $.004)$, following C-ADR versus ACDF, respectively [3].

- Rates of subsidence and disc migration reported by one study and were similar between groups at all followups (up to 60 months) [1].

- There was no difference between groups in the rate of dysphagia or dysphonia by 24 months in one study [1]. Rates were not reported past 24 months.

- Rates of World Health Organization grades 3 and 4 (serious) adverse events were similar in both groups at all follow-ups (up to 48 months) as reported by one study [2].

\section{Case series (Table 6)}

- One study reported increasing rates of heterotopic ossification (HO) with increased time: at 6 months, 54\% of spinal levels had evidence of HO compared with $88 \%$ of levels at 4 years [7]. Two other series reported $\mathrm{HO}$ rates in less than $40 \%$ of patients/levels between 4 and 8 years $[4,8,9]$. Rates of grade 4 severe $\mathrm{HO}$ (device immobilizaion) occurred in $0 \%-19 \%$ of patients as reported by three studies [4, 7, 9].

- One case series of 102 patients reported that by 4-6 years follow-up, $63.7 \%$ of patients had experienced at least one adverse event (112 events) [4].

- Rates of other adverse events as reported by one to five case series $4-8$ years postoperatively were relatively low [4-9]. 
Table 1 Subsequent operations following C-ADR versus fusion from two RCTs [1, 2] with follow-ups of 48 months or more.*

\begin{tabular}{|c|c|c|c|c|c|c|}
\hline & \multicolumn{3}{|c|}{$\begin{array}{l}\text { Burkus et al [1] (2010) } \\
60 \text { mo }\end{array}$} & \multicolumn{3}{|c|}{$\begin{array}{l}\text { Sasso et al [2] (2011) } \\
48 \text { mo }\end{array}$} \\
\hline & $\begin{array}{l}\text { C-ADR } \\
(n=276)\end{array}$ & $\begin{array}{l}\text { Fusion } \\
(n=265)\end{array}$ & $\boldsymbol{P}$ & $\begin{array}{l}\text { C-ADR } \\
(n=242)\end{array}$ & $\begin{array}{l}\text { Fusion } \\
(n=221)\end{array}$ & $\boldsymbol{P}$ \\
\hline Revisions $^{\dagger}$ & $0 \%(0)$ & $1.9 \%(5)$ & .028 & $0.4 \%(1)$ & $0 \%(0)$ & NS \\
\hline Hardware removal ${ }^{\ddagger}$ & $2.5 \%(7)$ & $4.9 \%(13)$ & NS & $1.7 \%(4)$ & $1.8 \%(4)$ & NS \\
\hline Supplemental fixation§ & $0 \%(0)$ & $1.9 \%(5)$ & .028 & $0 \%(0)$ & $2.3 \%(5)$ & NS \\
\hline External bone growth stimulator & $0 \%(0)$ & $2.6 \%(7)$ & .007 & $0 \%(0)$ & $0.9 \%(2)$ & NS \\
\hline Reoperation\| & $1.4 \%(4)$ & $0.8 \%(2)$ & NS & $1.7 \%(4)$ & $0.5 \%(1)$ & NS \\
\hline Adjacent-level surgery & $2.9 \%(8)$ & $4.9 \%(13)$ & NS & $4.1 \%(10)$ & $4.1 \%(9)$ & NS \\
\hline Nonadjacent-level surgery & NR & NR & - & $0.4 \%(1)$ & $1.4 \%(3)$ & NS \\
\hline
\end{tabular}

* C-ADR indicates cervical artificial disc replacement; NS, not statistically significant; and NR, not reported.

$\dagger$ Revisions: surgery that modified or adjusted the original implant.

‡ Hardware removal: removal of one or more components of the original implant followed by replacement with a different device.

$\S$ Supplemental fixation: surgery to provide additional stabilization to the index site (excluding external bone growth stimulators).

\| Reoperation: additional procedure at the index level besides a revision, hardware removal, or supplemental fixation.

Table 2 Causes and timing of subsequent reoperations following C-ADR versus fusion from two RCTs [1, 2] with follow-ups of 48 months or more.*

\begin{tabular}{|c|c|c|c|}
\hline & \multicolumn{3}{|c|}{ Reason for reoperation (No. of patients) } \\
\hline & Timing of reoperation, mo & C-ADR & ACDF \\
\hline Revisions $^{\dagger}$ & $\leq 24$ & $N R(1)[2]$ & $\operatorname{NR}(5[100 \%])[1]$ \\
\hline \multirow[t]{3}{*}{ Hardware removal $\left.\right|^{\ddagger}$} & $<24$ & $N R(3)[2]$ & NR (3) [2] \\
\hline & $24-48$ & Neck/shoulder pain (1 patient) [2] & $\operatorname{NR}(1)[2]$ \\
\hline & $0-60$ & Radicular pain (7 patients) [1] & Radicular pain (13) [1] \\
\hline \multirow[t]{3}{*}{ Supplemental fixation ${ }^{\S}$} & $<24$ & NA & NR (4) [2] \\
\hline & $24-48$ & NA & $N R(1)[2]$ \\
\hline & $0-60$ & NA & Symptomatic nonunion (5) [1] \\
\hline \multirow[t]{2}{*}{ External bone growth stimulator } & $<24$ & NA & NR (2) [2] \\
\hline & $0-60$ & NA & Suspected symptomatic nonunion (7) [1] \\
\hline \multirow[t]{3}{*}{ Reoperation"l } & $<24$ & NR (2) [2] & NR (1) [2] \\
\hline & $24-48$ & NR (2) [2] & NA \\
\hline & $0-60$ & NR (4) [1] & $\operatorname{NR}(2)[1]$ \\
\hline \multirow[t]{3}{*}{ Adjacent-level surgery } & $<24$ & $N R(6)[2]$ & NR (5) [2] \\
\hline & $24-48$ & $N R(4)[2]$ & $\operatorname{NR}(4)[2]$ \\
\hline & $0-60$ & ASD (8) [1] & $\operatorname{ASD}(13)[1]$ \\
\hline Nonadjacent-level surgery & $<24$ & $N R(1)[2]$ & NR (3) [2] \\
\hline
\end{tabular}

*C-ADR indicates cervical artificial disc replacement; ACDF, anterior cervical discectomy and fusion; NA, not applicable; NR, not reported; and ASD, adjacent segment disease. Numbers within brackets are references.

$\dagger$ Revisions: surgery that modified or adjusted the original implant.

‡ Hardware removal: removal of one or more components of the original implant followed by replacement with a different device.

§ Supplemental fixation: surgery to provide additional stabilization to the index site (excluding external bone growth stimulators).

I Reoperation: additional procedure at the index level besides a revision, hardware removal, or supplemental fixation. 
Table 3 Subsequent operations following C-ADR from four case series [4-7] with follow-ups of 48 months or more.*

\begin{tabular}{|c|c|c|c|c|c|}
\hline & $\begin{array}{l}\text { Goffin et al [4] } \\
\text { (2010), final } f / u: 4-6 y\end{array}$ & $\begin{array}{l}\text { Quan et al [5] } \\
(2011), f / u: 8 \text { y }\end{array}$ & $\begin{array}{l}\text { Robertson et al [6] } \\
\text { (2004), final f/u: } 4 y\end{array}$ & $\begin{array}{l}\text { Suchomel et al [7] } \\
(2010), f / u: 4 y\end{array}$ & $\begin{array}{l}\text { Summary } \\
4-8 y\end{array}$ \\
\hline & $\begin{array}{l}\text { C-ADR } \\
(n=102)\end{array}$ & $\begin{array}{l}\text { C-ADR } \\
(n=21)\end{array}$ & $\begin{array}{l}\text { C-ADR } \\
(n=17)\end{array}$ & $\begin{array}{l}\text { C-ADR } \\
(n=54)\end{array}$ & $\begin{array}{l}\text { C-ADR } \\
(n=194)^{\dagger}\end{array}$ \\
\hline Revisions $\ddagger$ & $0 \%(0)$ & $0 \%(0)$ & $0 \%(0)$ & $0 \%(0)$ & $0 \%(0)$ \\
\hline Hardware removalई & $2.0 \%(2)$ & $0 \%(0)$ & $6 \%(1)$ & $0 \%(0)$ & $1.5 \%(3)$ \\
\hline Supplemental fixation" & $0 \%(0)$ & $0 \%(0)$ & $0 \%(0)$ & $0 \%(0)$ & $0 \%(0)$ \\
\hline External bone growth stimulator & NR & NR & NR & NR & NR \\
\hline Reoperation? & $2.9 \%(3)$ & $0 \%(0)$ & $0 \%(0)$ & $0 \%(0)$ & $1.5 \%(3)$ \\
\hline Surgery at other cervical levels & $3.9 \%(4)$ & $0 \%(0)$ & $12 \%(2)$ & NR & $4.3 \%(6 / 140)$ \\
\hline Soft-tissue tumor excision & $1.0 \%(1)$ & NR & NR & NR & $1.0 \%(1 / 102)$ \\
\hline $\begin{array}{l}\text { Surgical evacuation of prevertebral } \\
\text { hematoma }\end{array}$ & $1.0 \%(1)$ & NR & NR & NR & $1.0 \%(1 / 102)$ \\
\hline
\end{tabular}

* C-ADR indicates cervical artificial disc replacement; NR, not reported; and f/u, follow-up.

$\dagger$ Unless otherwise indicated.

¥ Revisions: surgery that modified or adjusted the original implant.

$\S$ Hardware removal: removal of one or more components of the original implant followed by replacement with a different device.

II Supplemental fixation: surgery to provide additional stabilization to the index site (excluding external bone growth stimulators).

"Reoperation: additional procedure at the index level besides a revision, hardware removal, or supplemental fixation.

Table 4 Causes and timing of subsequent reoperations following C-ADR from four case series [4-7] with follow-ups of 48 months or more.*

\begin{tabular}{lll}
\hline & Timing of reoperation & Reason for reoperation (No. of patients) \\
\hline tHardware removal & $<24 \mathrm{mo}$ & Pain on full extension (1) [6] \\
& $6 \mathrm{y}$ & Progressive spinal cord compression due to recurrent posterior osteophyte formation (1) [4] \\
& NR & NR (1)[4] \\
\hline fReoperation & $<12 \mathrm{mo}$ & Unresolved radicular symptoms (laminoforaminotomy) (1) [4] \\
& $5.8 \mathrm{y}$ & NR (foraminotomy) (1) [4] \\
& $\mathrm{NR}$ & Myelopathy (laminectomy) (1) [4] \\
\hline Surgery at other cervical levels & $\leq 24 \mathrm{mo}$ & Removal of osteophytes present before original surgery (1) [6] \\
& $>4.5 \mathrm{y}$ & Myelopathy (laminectomy and fusion) (1) [6] \\
\hline
\end{tabular}

* C-ADR indicates cervical artificial disc replacement; NR, not reported; and numbers within brackets are references.

$\dagger$ Hardware removal: removal of one or more components of the original implant followed by replacement with a different device.

Supplemental fixation: surgery to provide additional stabilization to the index site (excluding external bone growth stimulators).

$\ddagger$ Reoperation: additional procedure at the index level besides a revision, hardware removal, or supplemental fixation. 
Table 5 Adverse events following C-ADR versus fusion from two RCTs [1-3] with follow-ups of 48 months or more.*

\begin{tabular}{|c|c|c|c|c|c|}
\hline & \multirow[t]{2}{*}{ Follow-up, mo } & \multirow[t]{2}{*}{ Studies } & \multicolumn{2}{|c|}{ Results (No. patients) $^{\dagger}$} & \multirow[t]{2}{*}{$\boldsymbol{P}$} \\
\hline & & & C-ADR & ACDF & \\
\hline \multirow[t]{3}{*}{ Subsidence f $^{\ddagger}$} & $\leq 24$ & $1[1]$ & $2.6 \%(5 / 190)$ & $4.9 \%(8 / 164)$ & NS \\
\hline & $24-36$ & $1[1]$ & $2.8 \%(4 / 141)$ & $0.9 \%(1 / 116)$ & NS \\
\hline & $36-60$ & $1[1]$ & $2.8 \%(2 / 71)$ & $1.4 \%(1 / 71)$ & NS \\
\hline \multirow[t]{3}{*}{ Implant migration } & $\leq 24$ & $1[1]$ & $0 \%(0 / 190)$ & $0 \%(0 / 164)$ & NS \\
\hline & $24-36$ & I[1] & $0 \%(0 / 141)$ & $0 \%(0 / 116)$ & NS \\
\hline & $36-60$ & $1[1]$ & $0 \%(0 / 71)$ & $0 \%(0 / 71)$ & NS \\
\hline Dyspagia or dysphonia§ & $\leq 24$ & $1[1]$ & $8.7 \%(17 / 190)$ & $8.3 \%(14 / 164)$ & NS \\
\hline \multirow[t]{2}{*}{ WHO grades 3-4 (serious) adverse events ${ }^{\ddagger}$} & $<24$ & $1[2]$ & $31.0 \%(75 / 242)$ & $27.6 \%(61 / 221)$ & NS \\
\hline & $24-48$ & $1[2]$ & $18.2 \%(44 / 242)$ & $16.3 \%(36 / 221)$ & NS \\
\hline Severe neck and arm pain & $24-48$ & $1[2]$ & $1.2 \%(3 / 242)$ & $2.3 \%(5 / 221)$ & NS \\
\hline New neurological deficits & $24-48$ & $1[2]$ & $0 \%(0 / 242)$ & $0.9 \%(2 / 221)$ & NS \\
\hline \multirow[t]{2}{*}{ Adjacent level ossification (any) } & 24 & $1[3]$ & $24 \%(5 / 21)$ & $64 \%(16 / 25)$ & .003 \\
\hline & 48 & $1[3]$ & $50 \%(10 / 20)$ & $82 \%(18 / 22)$ & .004 \\
\hline
\end{tabular}

* C-ADR indicates cervical artificial disc replacement; ACDF, anterior cervical discectomy and fusion; ns, not statistically significant; and WHO, World Health Organization.

$\dagger$ Rates are cumulative and reflect percentage of patients unless otherwise indicated.

‡ Rates are not cumulative.

$\S$ Authors did not differentiate between rates of dysphagia and rates of dysphonia. 
Table 6 Adverse events following C-ADR versus fusion from five case series [4-9] with follow-ups of 48 months or more.*

\begin{tabular}{|c|c|c|c|c|c|}
\hline & Follow-up & Studies & Patients, n & $\begin{array}{l}\text { Results, mean } \% \\
\text { patients }^{\dagger}\end{array}$ & $\begin{array}{l}\text { Results, range } \% \\
\text { patients }\end{array}$ \\
\hline Overall adverse events (cumulative) & $4-8 y$ & $1[4]$ & 102 & 63.7 & 63.7 \\
\hline \multirow[t]{4}{*}{ Subsidence ${ }^{\ddagger}$} & $4 y$ & $2[4,7]$ & 136 & 0 & 0 \\
\hline & $6 y$ & $1[4]$ & 77 & 0 & 0 \\
\hline & $8 y$ & $1[4]$ & 26 & 0 & 0 \\
\hline & $4-8$ y(pooled) & $2[4,7]$ & 136 & 0 & 0 \\
\hline \multirow[t]{3}{*}{ Implant migration/loosening } & $4-6 y$ & $3[4,6,7]$ & 173 & 1.7 & $0-6$ \\
\hline & $8 y$ & $1[5]$ & 21 & 5 & 5 \\
\hline & $4-8$ y (pooled) & $4[4-7]$ & 194 & 2.1 & $0-6$ \\
\hline Screw breakage & $4 y$ & $1[6]$ & 17 & 6 & 6 \\
\hline \multirow[t]{8}{*}{ Heterotopic ossification (any) } & $6 \mathrm{mo}$ & $1[7]$ & 54 (65 levels) & 54 levels & 54 levels \\
\hline & $1 y$ & $1[7]$ & & 72 levels & 72 levels \\
\hline & $2 y$ & $1[7]$ & & 78 levels & 78 levels \\
\hline & $4 y$ & $1[7]$ & 50 (60 levels) & 88 levels & 88 levels \\
\hline & $4 y$ & $1[4,8]$ & 102 & 34 & 34 \\
\hline & $5 y$ & $1[9]$ & 22 (24 levels) & 33 levels & 33 levels \\
\hline & $6 y$ & $1[4,8]$ & 77 & 38 & 38 \\
\hline & $8 y$ & $1[4,8]$ & 26 & 39 & 39 \\
\hline \multirow{8}{*}{$\begin{array}{l}\text { Heterotopic ossification (grade } 4 \text { [severe; device } \\
\text { immobilization] only) }\end{array}$} & $6 \mathrm{mo}$ & $1[7]$ & \multirow[t]{3}{*}{54 (65 levels) } & 0 levels & 0 levels \\
\hline & $1 y$ & $1[7]$ & & 8 levels & 8 levels \\
\hline & $2 y$ & $1[7]$ & & 19 levels & 19 levels \\
\hline & $4 y$ & $1[7]$ & 50 (60 levels) & 18 levels & 18 levels \\
\hline & $4 y$ & $1[4,8]$ & 102 & 5 & 5 \\
\hline & $5 y$ & $1[9]$ & 22 (24 levels) & 8 levels & 8 levels \\
\hline & $6 y$ & $1[4,8]$ & 77 & 8 & 8 \\
\hline & $8 y$ & $1[4,8]$ & 26 & 8 & 8 \\
\hline Dysphonia & $4-6 y$ & $3[4,6,7]$ & 173 & 1.7 & $0-12$ \\
\hline Severe neck and arm pain/brachialgia & $4 y$ & $1[6]$ & 17 & 12 & 12 \\
\hline New neurological deficits & $4-6 y$ & $2[4,7]$ & 156 & $\begin{array}{l}10 \text { events [study 4]; } \\
4 \text { [study 7] }\end{array}$ & $\begin{array}{l}10 \text { events [study 4]; } \\
4 \text { [study 7] }\end{array}$ \\
\hline Perioperative adverse events (details NR) & $4-6 y$ & $1[4]$ & 102 & 2.0 & 2.0 \\
\hline Splitting of vertebral bodies (perioperative) & $4 y$ & $1[7]$ & 54 & 4 & 4 \\
\hline Pain on full-neck extension & $4 y$ & $1[6]$ & 17 & 18 & 18 \\
\hline
\end{tabular}

* C-ADR indicates cervical artificial disc replacement; NR, not reported; and NS, not statistically significant.

$\dagger$ Rates are cumulative and reflect percentage of patients unless otherwise indicated.

$\ddagger$ Rates of subsidence at each follow-up; thus, subsidence rates are not cumulative. 


\section{CLINICAL GUIDELINES}

One guideline was found, published by the North American Spine Society (NASS) in 2010, titled "Diagnosis and treatment of cervical radiculopathy from degenerative disorders." Among the major recommendations listed were the following statements relevant to the topic of this review:

- "ACDF and total disc arthroplasty (TDA) are suggested as comparable treatments, resulting in similarly successful short term outcomes, for single level degenerative cervical radiculopathy." (grade: B; fair evidence-level II or III studies).

- "Surgery is an option for the treatment of single level degenerative cervical radiculopathy to produce and maintain favorable long term (> 4 years) outcomes." (grade C; poor quality evidence-level IV or V studies).

\section{CASE STUDY}

- A 43-year-old man presented with a left C6 radiculopathy secondary to a posterolateral disc herniation (Fig 2a).

- He failed conservative treatment and was treated with a C5-6 discectomy and placement of a metal-on-metal (Prestige ST, Medtronic, Memphis, TN, USA) total disc replacement.
- Postoperatively, he was permitted an early return to activities of daily living and was working 2 weeks following the procedure.

- Four years after the procedure, he remained pain free, had normal neurological function, and full functional activity (Fig $\mathbf{2 b - c}$ ).

\section{DISCUSSION}

In two RCTs with 4-5 years follow-up, the incidence and severity of adverse events are similar between C-ADR and ACDF and did not change between 2 and 4 (to 5) years follow-up [1-3]. A subset of patients from one RCT had lower rates of adjacent-level ossification at 4 years following C-ADR versus ACDF [3]. One cases series of C-ADR with 4 years follow-up heterotrophic ossification appears to increase over time [7]. Severe (grade 4) heterotopic ossification was reported to occur in $0 \%-19 \%$ of patients at 4 to 9 years follow-up [4-9]. Rates of other adverse events were relatively low at 4- to 9-year follow-up [4-9].

Unanticipated device-related complications have not been reported in C-ADR in two studies with 4- to 5-year followup. However, two cases of abnormal inflammatory reactions to metal ions with epidural spinal cord compression have been reported following cobalt-chrome metal on metal C-ADR, which appear similar to that seen following MOM total hip arthroplasty $[10,11]$.

\section{Fig 2}

a Magnetic resonance imaging showing large herniated disc (arrow) at C5-6.

b Four-year follow-up lateral $x$-ray after stainless steel on stainless cervical disc (Prestige ST, Medtronic, Memphis, TN, USA).

c Anteroposterior x-ray.
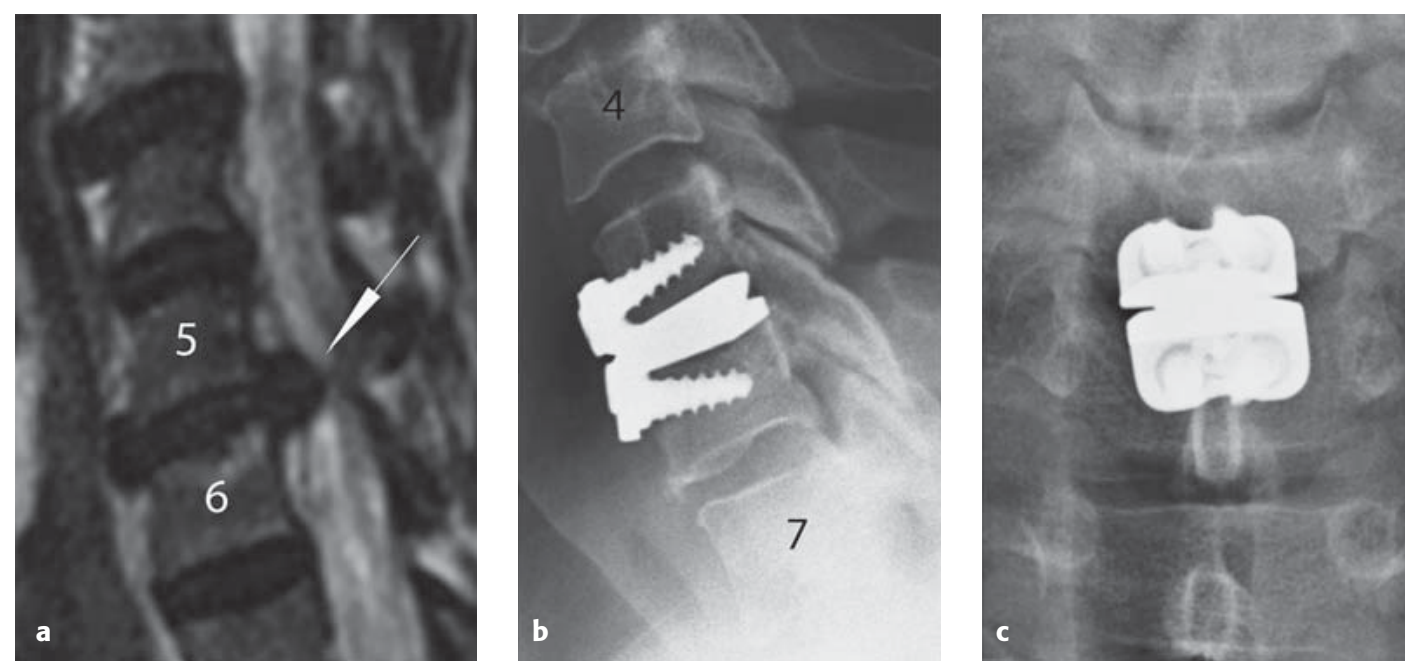
In the RCTs, secondary surgeries at the index level occurred between $0 \%$ and $3.9 \%$ after C-ADR and $5.4 \%$ and $12.1 \%$ after ACDF $[1,2]$. These rates were consistent with those reported in the observational studies. The causes for index level reoperation for C-ADR were persistent pain or recurrent pain and for ACDF were pseudarthrosis or need for hardware revision to treat adjacent segment degeneration.

\section{Strengths}

- Analysis included a large number of randomized patients

- Homogenous inclusion and exclusion criteria

- Adverse events were well documented with clearly defined definitions

\section{Limitations}

- Follow-up in RCTs was low at longer-term follow-up

- RCT data was available for only two studies

- No case reports of more serious adverse events occurring 4 years postoperatively were identified

\section{Clinical relevance and impact}

This review documents at 4- to 5-year follow-up the relative safety of C-ADR compared with ACDF for treatment of single-level myelopathy and/or radiculopathy. Further reoperation rates at the index level and secondary surgeries at adjacent levels of C-ADR are equal or lower than ACDF. Results of on-going clinical trials and longer follow-up are required for a better understanding of the long-term safety of C-ADR (Tables 7-8).

\section{SUMMARY AND CONCLUSIONS}

- Currently, approved FDA devices have long-term safety profiles equal to or better than ACDF.

- Long-term reoperation rates at both the index and adjacent levels following C-ADR are equal to or lower than those occurring after ACDF.

- Additional comparative studies are needed to have a better understanding of the long-term safety of C-ADR.

\section{EVIDENCE SUMMARY}

Table 7 Question 1: What evidence is available from studies of cervical artificial disc replacement (C-ADR) regarding the long-term complications? How do these rates change over time?

\begin{tabular}{lll}
\hline Outcomes & Strength of evidence & Conclusions/comments \\
\hline $\begin{array}{l}\text { Heterotopic ossification, } \\
\text { device-related events, } \\
\text { dysphagia/dysphonia, } \\
\text { other adverse events }\end{array}$ & $\begin{array}{l}\text { Fery low } \\
\text { Further research is very likely to have an important impact on our confidenced controlled trials and five case series } \\
\text { in the estimate of effect and is likely to change the estimate. }\end{array}$ & $\begin{array}{l}\text { reported long-term rates for a variety of adverse events } \\
\text { following C-ADR. Adjacent heterotopic ossification (HO) } \\
\text { rates were lower following C-ADR compared with fusion in } \\
\text { one small subset of an RCT, while three case series } \\
\text { reported long-term HO rates occurring in a range of } \\
33 \% \text {-88\% of treated levels. Rates of other adverse events } \\
\text { were generally low. }\end{array}$ \\
\hline
\end{tabular}

Table 8 Question 2: What are the rates and causes of second surgeries?

\begin{tabular}{lll}
\hline Outcomes & Strength of evidence & Conclusions/comments \\
\hline $\begin{array}{l}\text { Revisions, hardware } \\
\text { removal, supplemental } \\
\text { fixation, reoperation, } \\
\text { surgery at other levels }\end{array}$ & $\begin{array}{l}\text { Further research is very likely to have an important impact on our confidence } \\
\text { in the estimate of effect and is likely to change the estimate. }\end{array}$ & $\begin{array}{l}\text { Twized controlled trials and four case series } \\
\text { C-ADR. Rates of subsequent operations following C-ADR } \\
\text { were relatively low, and were similar to or lower than those } \\
\text { following fusion. Causes and timing of second surgeries } \\
\text { varied. }\end{array}$ \\
\end{tabular}




\section{REFERENCES}

1. Burkus JK, Haid RW, Traynelis VC, et al (2010) Long-term clinical and radiographic outcomes of cervical disc replacement with the Prestige disc: results from a prospective randomized controlled clinical trial. J Neurosurg Spine; 13(3):308-318.

2. Sasso RC, Anderson PA, Riew KD, et al (2011) Results of cervical arthroplasty compared with anterior discectomy and fusion: four-year clinical outcomes in a prospective, randomized controlled trial. J Bone Joint Surg Am; 93(18):1684-1692.

3. Garrido BJ, Wilhite J, Nakano M, et al (2011) Adjacent-level cervical ossification after Bryan cervical disc arthroplasty compared with anterior cervical discectomy and fusion. J Bone Joint Surg Am; 93(13):1185-1189.

4. Goffin J, van Loon J, van Calenbergh F, et al (2010) A clinical analysis of 4- and 6-year follow-up results after cervical disc replacement surgery using the Bryan Cervical Disc Prosthesis. J Neurosurg Spine; 12(3):261-269.

5. Quan GM, Vital JM, Hansen S, et al (2011) Eight-year clinical and radiological follow-up of the Bryan cervical disc arthroplasty. Spine (Phila Pa 1976); 36(8):639-646.

6. Robertson JT, Metcalf NH (2004) Long-term outcome after implantation of the Prestige I disc in an end-stage indication: 4-year results from a pilot study. Neurosurg Focus; 17(3):E10.

7. Suchomel P, Jurak L, Benes V 3rd, et al (2010) Clinical results and development of heterotopic ossification in total cervical disc replacement during a 4-year follow-up. Eur Spine J; 19(2):307-315.

8. Walraevens J, Demaerel $\mathbf{P}$, Suetens $\mathbf{P}$, et al (2010) Longitudinal prospective long-term radiographic follow-up after treatment of single-level cervical disk disease with the Bryan Cervical Disc. Neurosurgery; 67(3):679-687.

9. Zhao YB, Sun Y, Chen ZQ, et al (2010) Application of cervical arthroplasty with Bryan cervical disc: long-term $X$-ray and magnetic resonance imaging follow-up results. Chin Med J (Engl); 123(21):2999-3002.

10. Cavanaugh DA, Nunley PD, Kerr EJ 3rd, et al (2009) Delayed hyper-reactivity to metal ions after cervical disc arthroplasty: a case report and literature review. Spine (Phila Pa 1976); 34(7):E262-265.

11. Guyer RD, Shellock J, MacLennan B, et al (2011) Early failure of metal-on-metal artificial disc prostheses associated with lymphocytic reaction: diagnosis and treatment experience in four cases. Spine (Phila Pa 1976); 36(7):E492-497. 